\title{
Developing Adaptation and Adapting Development
}

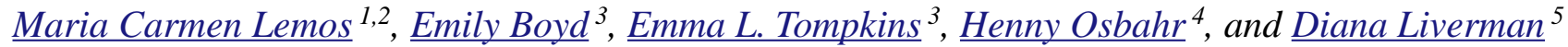

Key Words: adaptation; adaptive capacity; climate change; development; resilience.

Climate change is upon us. The fourth assessment report of the Intergovernmental Panel on Climate Change clearly describes the evidence of a changing climate (IPCC 2007a,b). Although scientists disagree about the extent to which these changes will happen, they do agree that there have been and will be changes in average climatic conditions, there will be changes in the frequency and intensity of weather hazards, already variable climates will become less predictable, and there is considerable uncertainty about the distribution and impact of these changes. Actions to reduce the human contribution to the changing climate are slowly happening, but they so far seem too few and too limited to make a significant difference to the climate change scientists predict. What has become clear is that people from all countries, from all income levels, and irrespective of capacity to do so, will have to adapt to these changes. The development and climate research communities have much to learn from each other in helping people with these adaptations.

The term adaptation refers to actions taken to adjust to the consequences of climate change, either before or after impacts are experienced. At the local level, impacts can be modulated by state interventions as well as through actions by communities, individuals, NGOs, and the private sector. Examples of adaptations include buildings that stay cooler and use less water to cope with higher summer temperatures and reduced precipitation, or agricultural diversification and water management to respond to increased risk of drought and floods. Building adaptive capacity, i.e., improving the capacity of individuals, companies and states to respond and to reduce their vulnerability to climate change, has emerged as a central element in climate change adaptation (IPCC 2007a).

Measuring what this capacity is and assessing how well it enables positive responses and recovery from diverse climate-related impacts has posed great research challenges. In part this is because capacity is a latent condition that can only be observed when realized through some form of concrete adaptation. Many human dimensions scholars presume that such capacity can be built by investing in the enhancement of individuals and systems' ability to withstand and recover from negative climate impacts or shocks to the system. As such, there is agreement among most scholars of adaptation that adaptive capacity can be created by: (1) investing in information and knowledge, both in their production and in the means of distributing and communicating them; (2) encouraging appropriate institutions that permit evolutionary change and learning to be incorporated; and (3) increasing the level of resources such as income and education to those in which they are presently lacking (Janssen and Ostrom 2006).

Although many of these ideas are not new, they have been part of the development discourse and practice for many years. Indeed, they have been essential elements of numerous programs and policies to reduce poverty and build capacity to respond to different kinds of stressors such as economic crisis, natural disasters, or political strife. What is new is that these elements of development and capacity building are re-emerging in the unique context of climate change. Climate change causes direct stress and accentuates indirect stress on already vulnerable people and the resources on which they depend. For

\footnotetext{
${ }^{1}$ James Martin 21st Century School Fellow, Environmental Change Institute, Oxford University Centre for the Environment, Oxford, OX1 3QY, UK,

${ }^{2}$ School of Natural Resources and Environment, University of Michigan, Ann Arbor, MI, USA., ${ }^{3}$ James Martin 21 st Century School Fellow, Environmental Change Institute, Oxford University Centre for the Environment, South Parks Road, Oxford, UK OX1 3QY, ${ }^{4}$ Tyndall Centre Research Fellow,

Environmental Change Institute, Oxford University Centre for the Environment, South Parks Road, Oxford, UK OX1 3QY, ${ }^{5}$ Director, Environmental Change Institute, Environmental Change Institute, Oxford University Centre for the Environment, South Parks Road, Oxford, UK OX1 3QY
} 
many years, the development community has sought to facilitate development in the face of wars, famines, plagues, epidemics, global economic recessions, restructurings, natural hazards, and other stressors. However, these stressors have different characteristics from climate change, and it is for this reason that the links between the development and adaptation communities have to be forged. The development community must learn about the unique ability of climate change to compromise effective sustainable development, and the climate adaptation community can learn from the processes of building adaptive capacity implemented in the past. Because the development and climate impacts communities both have long term concerns for understanding response to disaster, we suggest this is an area where the most productive collaborations between the two communities can begin in research and practice.

Climate change will bring two potentially significant development challenges to less developed countries (LDCs). First, the nature and extent of the weather and climate related stressors already affecting vulnerable populations in LDCs such as crop losses, displacement, and lack of access to clean water that may lead to poverty, famine, and even death will become more severe under climate futures. Both the level of risk faced by vulnerable populations, and the number of people at risk, may grow if no proactive capacity building to respond to these additional stressors takes place.

Second, development policy will have to pay attention to specific vulnerabilities associated with the sensitivity of particular populations to climate impacts that may not have been in the agenda in the past. These include taking care of people living in coastal areas, lowlands, drought, and flood prone regions or people whose livelihoods directly depend on resources that are going to be negatively affected by climate change. Although policymakers often approach the former through risk management, addressing the underlying conditions of existing vulnerabilities, e.g., those likely to be exacerbated by climate change, has proven to be much harder for development practioners.

These general vulnerabilities are symptoms of much deeper socioeconomic and political inequalities that have historically plagued the less developed world. Although it is not our goal to equate adaptation to development, we suggest that in order to be effective, adaptive capacity building for adaptation and development needs to squarely address the structural inequalities that create and sustain poverty, constrain access to resources and threaten their long-term sustainability. Theorizing about the attributes of adaptive capacity is important, but the real challenge and potential impediment to successful adaptation is how to realize adaptive capacity in very inhospitable conditions. Addressing inequalities may require policies that profoundly challenge the current distribution of power and assets across societies. It may require implementing deep reforms, such as income or land distribution/ redistribution, fairer trade, universal access to education, and health services, and the deepening of democratic institutions through societal participation and accountability.

The critical question seems to be how to integrate development planning and climate adaptation policy in ways that avoid the pitfalls of past failed development practices while promoting positive synergies. We propose that adaptive capacity building can be delivered through a two-tiered approach that focuses on developing effective disaster management to climate related hazard, and implementing policy reform that addresses deeper structural inequalities that are often at the heart of entrenched vulnerabilities. Although policy intervention to build adaptive capacity should happen at multiple levels to be effective (Adger et al.2005), local level interventions can often produce the most effective synergies between disaster risk management and structural reform aimed at addressing inequalities.

Local disaster risk management programs can incorporate well-tested good governance practices that: pave the way for deeper reform; contribute to the enhancement of livelihoods through building natural, produced, human, social and cultural capitals (Bebbington 1999); and thus give the vulnerable not only the capability to adapt but also to mobilize for the kind of change that will further build their adaptive capacity. Examples of this type of approach already exist. In drought ravaged NE Brazil, drought response programs have increased adaptive capacity by subscribing to participatory decision making schemes, creating accountable and transparent organizations and institutions, investing in long term planning, and building learning features into managing institutions (Lemos 2003). Here, local scale capacity building has simultaneously reduced sensitivity to climate variability and change and built overall capacity for decision making 
among vulnerable groups. In Africa, several countries are already integrating climate risk management into development planning; examples include efforts to address flood management in Mozambique, malaria control in southern Africa and drought in Malawi and Kenya (Osbahr and Vinner 2006, Hellmuth et al. 2007).

The development community can clearly guide the adaptation community in how to best build capacity and the adaptation community can contribute its understanding of the unique stresses associated with climate change. This symbiotic relationship can profit from empirical research that systematically and purposefully identifies the markers of success within development programs across different policy systems, climates, and geographies to avoid making the mistakes made by development programs in the past. For example, development research shows that investments in good governance such as participatory development, investment in social networks, and provision of information, technologies, and new institutions for resource management, often fail if they do not redress the fundamental structural problems that are at the root of poverty. The experience of the Green Revolution in Latin American and Asia shows how a programme designed to adapt and improve basic grain production in the context of harsh climates and disease encountered problems in helping the poorest rural people who did not have access to the land, water, and inputs needed to benefit from the development programmes (Conway 1997). In Africa development experiences are fraught with examples of the "tyranny of participation" in which inclusive governance systems, e.g., adaptive comanagement, are introduced without addressing continuity of infrastructural support, rights, and embedded power inequalities in the process of decentralization (Ribot 1999). Many of these processes end up captured by local elites and fall short from their goal of enhancing accountability and democracy. It is important to understand empirically how these challenges can be overcome, especially in cases in which building adaptive capacity involves redistributive policymaking that can be met by fierce political opposition.

To face these and other challenges, it is time to bring the development and adaptation communities together in a constructive engagement of mutual learning and practice and to the realization that the process of adaptation to climate change does not need to start from scratch. Given the urgency of climate change and the high likelihood that it will seriously affect developing countries, new forms of governance are needed at local and national levels to address disaster risk management and structural reform. Formulating systems of governance to address and build adaptive capacity among states, businesses, scientists, and individuals can constructively draw from the vast development experience of building capacity for people and communities coupled with new knowledge about climate change and its impacts.

Responses to this article can be read online at:

http://www.ecologyandsociety.org/voll2/iss2/art26/responses/

\section{LITERATURE CITED}

Adger, W. N., N. W. Arnell, and E. L.Tompkins. 2005. Successful adaptation to climate change across scales. Global Environmental Change 15:77-86.

Bebbington, A. 1999. Capitals and capabilities: a framework for analyzing peasant viability, rural livelihoods and poverty. World Development 27 (12):2021-44.

Conway, G. 1997. The doubly green revolution: food for all in the 21st century. Penguin, London, UK.

Hellmuth, M. E., A. Moorhead, M. C. Thomson, and J. Williams, editors. 2007. Climate risk management in Africa: learning from practice. International Research Institute for Climate and Society (IRI), Columbia University, New York, New York, USA.

Intergovernmental Panel on Climate Change (IPCC). 2007a. Climate change 2007: impacts, adaptation and vulnerability. Working Group II Contribution to the Intergovernmental Panel on Climate Change Fourth Assessment Report. IPCC, Geneva, Switzerland.

Intergovernmental Panel on Climate Change (IPCC). 2007b. Climate change 2007: the physical science basis: summary for policymakers. Contribution of Working Group I to the Fourth Assessment Report of the Intergovernmental Panel on Climate Change. IPCC, Geneva, Switzerland. 
Janssen, M. A., and E. Ostrom, editors. 2006. Resilience, vulnerability, and adaptation: a crosscutting theme of the International Human Dimensions Programme on Global Environmental Change Global Environmental Change 16 (3):235-316.

Lemos, M. C. 2003. A tale of two policies: the politics of seasonal climate forecast use in Ceará, Brazil. Policy Sciences 32(2):101-123.

Osbahr, H., and D. Vinner. 2006. Linking climate change adaptation and disaster risk management for sustainable poverty reduction: Kenya case study. Vulnerability and Adaptation Resource Group (VARG), European Commission Report, Geneva, Switzerland. Available online at: http://www.clima tevarg.org/essd/env/varg.nsf/42ec25f6537f5eff852 56dab0048d8e9/b603b3c185bee77485256dab0059aca8/ \$FILE/EC\%20VARG\%20Kenya\%20Report.pdf.

Ribot, J. 1999. Decentralisation, participation, and accountability in Sahelian forestry: legal instruments of political-administrative control. Africa 69 (1):23-65. 